
e-ISSN 2016/Atual: 2525-7870 | e-ISSN 2015/2016: 2447-018X

\title{
Enseñanza de Español para Niños: Adquiriendo la L2 a través de Canciones
}

\author{
Ensino de Espanhol para Crianças: Adquirindo a L2 através de Músicas \\ Teaching Spanish for Children: Acquisition the L2 Through Songs
}

Millaine de Souza Carvalho ${ }^{1}$

Lic. Nathalia Madeira Araujo ${ }^{2}$

\begin{abstract}
Resumen
El presente estudio busca reflexionar acerca de la adquisición/aprendizaje de segunda lengua (L2), bien como sobre metodologías de trabajo para enseñanza de L2 a niños que están en proceso de alfabetización en su lengua materna. Por eso, en este trabajo, pensamos la enseñanza de la lengua española solamente a través de la oralidad. Con este foco, impartimos clases a niños de una escuela particular de la ciudad de "Jaguarão", en el "Rio Grande do Sul". A partir de esta práctica, percibimos que los estudiantes que tienen contacto desde temprano con la lengua española por medio de la oralidad adquieren/aprenden, con más facilidad la L2 estudiada.
\end{abstract}

Palabras clave: Adquisición/Aprendizaje; Oralidad; Español para niños.

\section{Resumo}

O presente estudo busca refletir acerca da aquisição/aprendizagem de segunda língua (L2), bem como sobre metodologias de trabalho para o ensino de L2 a crianças que estão em processo de alfabetização na sua língua materna. Por isso, neste trabalho, pensamos no ensino na língua espanhola somente através da oralidade. Com este foco, ministramos aulas a alunos de uma escola particular da cidade de Jaguarão, no Rio Grande do Sul. A partir desta prática, percebemos que os estudantes que têm contato desde cedo com a língua espanhola por meio da oralidade adquirem/aprendem, com más facilidade a L2 estudada.

Palavras-Chaves: Aquisição/Aprendizagem; Oralidade; Espanhol para crianças.

\begin{abstract}
This study seeks to reflect about the acquisition/learning of the second language (L2), as well as about work methods for the L2 teaching, to the children who are in the literacy process in their mother tongue. Therefore, in this paper, we thought the Spanish language teaching just through the orality. With this focus, we ministered classes to a private school's children in the city of Jaguarão - Rio Grande do Sul. From this practice, we perceived that the students who have early contact with the Spanish Language by means of the orality acquire/learn more easily the L2 studied.
\end{abstract}

Keywords: Acquisition/Learning; Orality; Spanish for children.

\footnotetext{
${ }^{1}$ Graduanda em Letras Português e Espanhol; Universidade Federal do Pampa - Unipampa; Jaguarão, Rio Grande do Sul, Brasil; millainedescarvalho@gmail.com.

${ }^{2}$ Licenciada em Letras Português e Espanhol, mestranda em Letras; Universidade Católica de Pelotas - UCPel; Pelotas, Rio Grande do Sul, Brasil; naty_araujo@hotmail.com.
} 


\section{Introducción}

El presente trabajo, utilizando las teorías estudiadas en la asignatura de metodología de enseñanza de español para niños y de adquisición/aprendizaje del lenguaje, busca reflexionar acerca de la adquisición/aprendizaje de segunda lengua (L2), en este caso la lengua española, a través de canciones y materiales didácticos, entendidos como recursos de los más variados tipos. Cabe resaltar que comprendemos por lengua segunda "[a]quella que cumple una función social e institucional en la comunidad lingüística en que se aprende" (GARGALLO, 1999, p. 21).

A partir de observaciones hechas en clases del Laboratorio de Español para Niños, vinculado al curso de Licenciatura en Letras - Portugués y Español, de la Universidade Federal do Pampa (UNIPAMPA), Campus Jaguarão; y de clases de español impartidas, por nosotras, a estudiantes, en una escuela particular de esta ciudad, reflexionaremos sobre metodologías de trabajo para enseñanza de L2a individuos en proceso de alfabetización. Además de llevar en consideración la producción de materiales didácticos y el uso de canciones en clases de español destinadas a niños.

Este artículo fue producido para la asignatura Metodología de Enseñanza de Español para Niños, componente curricular obligatorio de grado y Universidad, ya mencionados. Primeramente, presentaremos la fundamentación teórica relevante para este estudio y explicaremos porque consideramos, en este caso, es español como L2. Después, describiremos la observación hecha en el Laboratorio de Español para Niños. En secuencia, hablaremos como ocurrió el desarrollo de las clases impartidas en una escuela de "Jaguarão".

\section{Fundamentación teórica}

La ciudad de Jaguarão hace frontera con Río Branco, perteneciente a Uruguay. Entonces se puede decir que tanto los alumnos del Español para Niños, como los de las escuelas de Jaguarão, están ubicados en este contexto fronterizo, donde hay la influencia de por lo menos dos lenguas (portugués y español). Por haber en la Unipampa/Jaguarão alumnos uruguayos; brasileños estudiando en Rio Branco; personas que atraviesan la frontera para trabajar; comprendemos que, en este contexto, la Lengua Española tiene una función social e institucional (GRAGALLO, 1999), siendo así, podemos considerarla como una L2.

Para reflexionar acerca de la enseñanza de español a niños utilizamos la perspectiva teórica de la adquisición/aprendizaje de lenguaje. Carione, en el texto Aquisição de Segunda Língua: A Teoria de Krashen, aborda las cinco hipótesis propuestas por este autor. Según Carione, para Krashen, la adquisición es un proceso subconsciente, ocurre por la necesidad de 

e-ISSN 2016/Atual: 2525-7870 | e-ISSN 2015/2016: 2447-018X

comunicación de individuos, se resume en saber utilizar la lengua, siendo el aprendizaje un proceso consciente, que ocurre por esfuerzo propio del estudiante, es saber sobre la lengua. Esta distinción hecha entre adquisición/aprendizaje configura la primera hipótesis de Krashen.

La segunda hipótesis de Krashen es del orden natural. Esta habla acerca de la existencia de un orden natural para adquisición/aprendizaje de una L2. Para él, semejante como adquirimos/aprendemos nuestra lengua materna, adquirimos/aprendemos otra lengua.

La tercera, es la hipótesis del Input, según esta, el profesor debe ofrecer a los alumnos el input (insumos) que sean de buena calidad para proporcionar un buen espacio de adquisición/aprendizaje a los estudiantes. Así, ellos pasarán de un estado actual de lengua para uno más avanzado, es necesario ofrecer el input+1, o sea, siempre el input debe tener información linguiística nueva. Siendo la cuarta hipótesis la del monitor. En esta, con base en el aprendizaje, el hablante que está en el proceso de aprendizaje de Lengua Española va a corregirse siempre que considerar necesario. O sea, el Monitor actúa como una especie de fiscal mientras ocurre la utilización de la lengua.

La quinta y última hipótesis es la del filtro afectivo, conforme ella, los individuos con actitudes positivas en relación a la lengua extranjera tendrán más facilidad para aprenderla porque buscan más input, cuanto más bajo el filtro afectivo del alumno, más él aprende/adquiere. Al revés los estudiantes que tienen el filtro afectivo elevado, no aprenderán con gran efectividad. Krashen apunta que el mejor profesor es aquél que ofrece el input correcto al alumnado, que puede tornar ese input lo más comprensible posible y en condiciones de baja ansiedad. Según Krashen, en L2 y en lengua materna, adquisición tiene más valor que aprendizaje, siendo que hay dos condiciones esenciales para la adquisición: una exposición suficiente a input compresible contiendo i+1 (input más uno) y una situación psicológica favorable, con un bajo filtro afectivo que permita la asimilación del input comprendido.

Johnson (1997a), discute el concepto "adquisición del lenguaje" y afirma ser este el modo como los individuos adquieren un idioma, a través del contacto real con el uso de la lengua estudiada. La adquisición de una L2 exige que, primeramente, los niños adquieran la lengua, antes de estudiar acerca de esta. Para el autor, esta adquisición es posible, visto que, de acuerdo con él, los niños poseen una predisposición genética al adquisición/aprendizaje de lenguas.

Krashen, como ya expuesto, hace distinción entre los conceptos adquisición y aprendizaje, al paso que, para Johnson (2008),“estas experiencias sugieren que cuando intentamos dominar un idioma interviene un poco de aprendizaje y un poco de adquisición” 
(p.128). Así, de acuerdo con los estudios de Johnson, en este estudio, vamos a utilizar los términos adquisición y aprendizaje como sinónimos.

\section{Descripción de la experiencia}

\subsection{Observación hecha en el laboratorio de español para niños}

Para la realización de este trabajo, antes de que impartiéramos clase, hicimos observaciones en el Laboratorio de Enseñanza de Español para Niños. Fueron hechas tres observaciones, siendo que estas ocurrieron los días catorce (14) de junio, veintiún (21) de junio; y, la última, el diecinueve (19) de julio de dos mil catorce (2014).

El catorce (14) de junio de dos mil catorce, los becarios de este proyecto han trabajado con el léxico alimentario. Para eso, los profesores hicieron una receta de pan. La receta fue pegada a la pizarra. Al paso que la profesora colocaba los ingredientes en un recipiente, hablaba los nombres de ellos a los estudiantes, de modo que pudiesen aprenderlos. Todos estaban de delantal, los profesores y los niños, de modo que los estudiantes pudiesen sentirse involucrados en la situación.

Después, fue presentada una canción que hablaba el nombre de las comidas. Los chicos la cantaban mientras una de las profesoras hacía el pan. Uno de los objetivos de esta clase era que los alumnos aprendiesen el léxico de las comidas a través de la oralidad. Cuando los ingredientes estaban mezclados, cada alumno recibió un pedazo de la maza para sobarla. Fue perceptible que los niños cantaban, espontáneamente, la canción oída.

Mientras el pan estaba en el horno, los profesores propusieron hacer un juego de la memoria. En este juego ellos abordaron cuestiones envolviendo alimentación saludable o no saludable. Para eso utilizaron la canción A mí me gustan las hamburguesas. Al final, cada niño recibió su pan para llevar para casa.

La segunda observación ocurrió el día veintiún (21) de junio de dos mil catorce. El tema central de la clase fue la Copa del Mundo que estaba ocurriendo en Brasil. La televisión que hay en el Laboratorio fue prendida, pues estaba ocurriendo un partido de fútbol. En diapositivas, los profesores pusieron una imagen de un campo de fútbol, siendo que, en esta había el nombre de las posiciones que los jugadores ocupan en el campo.

Durante la realización de esta actividad, uno de los profesores preguntaba cómo se decía los nombres de las posiciones en portugués y cuál su función. Después, fueron abordadas cuestiones históricas de Copa de Mundo, sobre todo en lo que se refiere a Uruguay. Constatamos que, muchas veces, el alumnado, contestaba, en portugués, a los profesores, aunque los profesores hablaban solamente en español. 
Los alumnos preguntaron si iban a escuchar canciones, hablaron que les gusta mucho oír canciones en español. Los profesores pusieron la canción Unidos campeones, de Sergio Colombo, acerca de fútbol. Luego, los estudiantes pintaron un dibujo mientras escuchaban esta canción. El dibujo era de la mascota de la Copa, el Fuleco, explicaron que el nombre Fuleco es derivado Fule $=$ Fútbol + Eco $=$ Ecología . Percibimos que algunos empezaron a cantar el refrán, aunque no conocían la canción.

Al final de la clase, los profesores y alumnos, juntos, colorearon la bandera de Uruguay. Ellos preguntaron a los alumnos qué es la Celestre. Después, explicaron para los estudiantes que la selección uruguaya es conocida como Celeste. Mientras todos coloreaban, escuchaban, nuevamente, la canción oída anteriormente. Los niños, entonces, oyeron el Himno Nacional de Brasil, Uruguay, el canto yaguarense y el de Río Grande del Sur.

La tercera y última observación fue hecha el día diecinueve (19) de julio de dos mil catorce (2014). Esta clase fue empezada con los profesores preguntando qué frutas a los alumnos les gustan. Los estudiantes hablaron, en español, los nombres de las frutas que les gustan o no. Después, miraron un video cuya la temática era las frutas y escucharon nuevamente la canción para que todos la cantaran juntos.

Los niños cantaban el refrán de la música. La profesora dijo para los estudiantes que iban a hacer compras. Entonces, preguntó cuál es la moneda utilizada en Brasil y cuál se usa en Uruguay. Para la actividad de compras, recibieron dineros de papel, de modo que ellos pudiesen comprar las frutas en la frutería de juguete.

Continuadamente, los alumnos, uno a uno, hicieron compras en la frutería. Cada niño contaba para el grupo qué había comprado. Sabiendo los nombres de las frutas, los estudiantes, vendados, tuvieron que comer dos frutas distintas y hablar, en español, el nombre de las frutas. Se percibió que los alumnos estaban motivados a participar de las actividades, también, pues, fueron involucrados en una situación recurrente en sus vidas.

Por fin, los profesores presentaron el video de una fruta distinta a todos, lúcuma. Los maestros trabajaron todas las partes de esta música, preguntando para los alumnos todo que aparecía en la letra de la canción infantil El twist de las frutas. Notamos la participación de los estudiantes en esta actividad. Ellos respondían a todo lo que les era preguntado, también preguntaban el significado de las palabras desconocidas a ellos, bien como su pronunciación.

\subsection{Clases de español para niños impartidas en una escuela particular}

El veintisiete (27) de agosto de dos mil catorce (2014), nosotras ministramos clases en una escuela particular de la ciudad de Jaguarão. Utilizando dos clases cedidas por una 
profesora de lengua española, que posee grado en "Licenciatura em Letras - Português e Espanhol”, por la Universidade Federal do Pampa, Campus “Jaguarão”. Actualmente, ella hace maestría en enseñanza de lenguas en la misma Universidad.

La escuela se localiza en una zona central de esta ciudad, ofrece enseñanza primaria y secundaria, siendo que la lengua española es trabajada en todos los años de esos dos ciclos de la educación. Los alumnos son oriundos de clase socio-económica mediana. Impartimos clases para el primero y segundo años de la enseñanza fundamental. En el primer año había once alumnos. Al paso que en el segundo año había seis.

Para realización de estas clases, hicimos un juego. Fue hecho un lobo en un cartel, bien como las ropas del lobo. La actividad consistía en escuchar, con el alumnado, la canción Juguemos en el bosque. Después de escucharla preguntamos, al grupo, acerca de qué hablaba la canción. Cuando los alumnos hablaron que el lobo se ponía ropas, preguntamos qué ropas este ponía. De modo que los alumnos pudiesen adquirir los nombres de las ropas, inconscientemente, y relacionarlos a sus imágenes.

Trabajamos parte a parte la canción, escuchándola con los alumnos, inúmeras veces. Percibimos que aunque no conocían la canción trabajada, ellos empezaban a cantarla. De modo que la pusimos nuevamente para que la cantásemos. Después que hemos escuchado la canción trabajada, los estudiantes, con los ojos vendados, tendrían que sacar una pieza de ropa de una mesa y ponerla en el lobo que estaba pegado en la pared. Los niños se volvieron muy contentos y motivados, todos querían participar. Siendo que, las ropas utilizadas para vestir el lobo son las que aparecen en la canción.

Siguiendo el enfoque de la adquisición del lenguaje, según Carioni (1998), a partir de la teoría de Krashen, trabajamos solamente con la oralidad, partiendo del principio de que estuvimos impartiendo clases a niños en período de alfabetización en su lengua materna. Bien como creemos que no debemos utilizar la escritura.

Así, pensamos que cuanto más temprano el alumno sea expuesto a la nueva lengua, más fácilmente la adquirirá. Conforme apunta Garboggini, Perissé, Vieira,

[s]e uma criança é exposta desde cedo a falantes proficientes que interagem naturalmente com ela em uma língua estrangeira de maneira vivencial, a criança pode, de fato, vir a tornar-se mais competente do que um adulto que aprende o idioma em cursos de língua estrangeira. (2002, p. 20)

De ese modo, es notable la relevancia de la enseñanza de la lengua española a personas desde niñas. Sin embargo, los componentes lingüísticos no deben estar, 
explícitamente, en las clases, para no ocurrir interferencia de la L2 estudiada frente su lengua materna. Visto que los alumnos, en el primer ciclo de la enseñanza fundamental, están en proceso de alfabetización.

\section{Conclusões}

A partir de las observaciones hechas en el Laboratorio de Español para Niños y con base en las metodologías estudiadas en la asignatura Metodología de Enseñanza de Español para Niños, elaboramos una clase destinada a estudiantes del primer ciclo de la enseñanza fundamental, con foco en la oralidad. Trabajamos con los alumnos solamente a través de la oralidad ancorándonos en Garboggini, Perissé, Vieira (2002). Según ellas (2002), el lenguaje escrito es un lenguaje artificial, de modo que lo aprendemos solamente después del oral. Siendo que el aprendizaje del lenguaje escrito ocurre por intervención pedagógica, no naturalmente.

Entonces, siguiendo este razonamiento, adquirimos nuestra lengua materna en el contacto con los padres, familiares, cuidadores, con el propósito de establecer la comunicación inmediata, para que, solamente después de que vayamos a la escuela, pasemos a estudiar las estructuras formales de la lengua; en este segundo momento, aprendimos sobre esta lengua. Siendo así, el mismo movimiento debe ser hecho en la enseñanza de una L2. Primeramente, la adquirimos de forma oral, aprendemos a usarla, para, logo, estudiar sobre esta. Esto es lo que ocurre en esta escuela, en que los niños del primero al quinto año solamente tienen contacto con la Lengua Española por medio de actividades que enfocan la oralidad.

Además, las académicas de la carrera de Letras pudieron percibirse como futuras docentes de lengua española. También pudieron percibir que el input lingüístico propiciado a través de canciones, actividades fue fácilmente adquirido por estos niños. Aun, la facilidad con que los estudiantes adquieren la lengua española a través de canciones les sorprendió, pues observaron que el alumnado del primer ciclo de la enseñanza fundamental acepta, con más facilidad, actividades distintas al tradicional, sin vergüenza o prejuicios. Así, es notable que el nivel de motivación de los niños es uno de los factores que influyen directamente en la enseñanza/aprendizaje de una L2.

A seção de conclusões não é obrigatória. Embora esta possa rever os pontos principais do artigo, não repita o resumo como conclusão. A conclusão deve discorrer sobre a importância do trabalho ou sugerir aplicações e extensões. Indique de forma clara as vantagens, as limitações e as possíveis aplicações. As conclusões devem responder às questões da pesquisa, correspondentes aos objetivos e hipóteses; devem ser breves podendo 
apresentar recomendações e sugestões para trabalhos futuros; para artigos de revisão deve-se excluir material, método e resultados.

\section{Referências}

A Mí ME GUSTAN LAS HAMBURGUESAS. Disponible en:

$<$ http://www.vagalume.com.br/los-pirata/a-mi-me-gustan-las-hamburguesas.html>. Acceso en: 25 mayo 2015.

EL TWIST DE LAS FRUTAS. Disponible en:

<http://www.youtube.com/watch?v=U9W5W1CZiUs>. Acceso en: 25 mayo 2015.

CARIONI, L. Aquisição de segunda língua: a teoria de Krashen. In: BOHN, H.; RICHARDS, J. C.; LOCKHART, C. Estrategias de reflexión sobre la enseñanza de idiomas. España: Cambrige University Press, 1998. p. 50-74.

GARBOGGINI, I.; PERISSÉ, P.; VIEIRA, W. Língua Estrangeira: quando e como começar? Presença pedagógica. Ed, v. 8., n. 45, maio/junho, 2002, p. 18-27. Dimensão

GARGALLO, I. S. Lingüística aplicada a laenseñanza: aprendizaje del español como lengua extranjera. Madrid: Arco libros, 1999.

JOHNSON, K. Aprender y enseñar lenguas extranjeras: una introducción. México: Fundación de Cultura Económica - FCE, 1997.

Aprender y enseñar lenguas extranjeras: una introducción (Trad. Beatriz Álvarez Klein). México: Fundación de Cultura Económica - FCE, 2008.

JUGUEMOS EN EL BOSQUE.Disponible en:

<http://letrascancionesinfantiles.com/juguemosenelbosque/>. Acceso en: 25 mayo 2015. 